\title{
Analysis of Operation Rules of Provincial Peak Shaving Auxiliary Service Market
}

\author{
Wang Xingkai ${ }^{1, \mathbf{a}^{*}}$, Tang Yijin ${ }^{\mathbf{1 , b}}$ and Li Hongze ${ }^{\mathbf{1 , c}}$ \\ ${ }^{1}$ School of economics and management, North China Electric Power University, Changping District, Beijing, China
}

\begin{abstract}
In order to implement the requirements of the power system reform, to ensure the safety, stability and economic operation of the power system, and to promote the consumption of new energy, all provinces in China have built the peak-control auxiliary service market, and explore the establishment of a new mechanism for sharing and sharing of peak-control auxiliary services. Based on the operating rules of the peaking auxiliary service market in Xinjiang, Shanxi, Gansu, Fujian, Jiangsu, Jiangxi, Northeast, Anhui, Ningxia, Shanghai, Shandong and other places, the author compares and evaluates the key content of the market operating rules from four aspects: market members and their responsibilities, deep peaking transaction details, emergency start-stop peaking transaction details, and measurement and settlement, and also finds a direction for the provinces to revise or adjust the rules of peaking auxiliary services in the future for the reference of power grid dispatching, power plant operations and other departments, in order to improve the understanding of relevant personnel of the peaking auxiliary service market.
\end{abstract}

\section{Introduction}

The 19th CPC National Congress report pointed out that it is necessary to "promote a revolution in energy production and consumption to build a clean and lowcarbon, safe and efficient energy system". Promoting the development of renewable clean energy is an important task to improve the energy structure, ensure energy security and promote the construction of ecological civilization. At present, the development of wind energy in China ranks first in the world, with a huge installed capacity. In Anhui, for example, as of the end of 2018, the Anhui power grid dispatch caliber wind and wind total installed capacity of 10.941 million kilowatts, an increase of $23.8 \%$. However, with the large-scale access to wind power, wind energy, due to its inherent randomness and uncertainty, makes the output of wind turbines unstable and unpredictable power, resulting in new challenges to the traditional grid dispatch management model. In the spring and autumn season, when new energy is available, it has become normal for thermal power units to peak in depth, and even temporary shutdowns have to be arranged for thermal power units, and the large number of heating units in the northern region has exacerbated the contradiction of grid peaking. The essence of the peaking problem is the competition between various power sources for limited power generation space and the distribution of benefits. The current Interim Measures on the Management of Auxiliary Services for Grid-connected Power Plants was issued in 2006, and corresponding implementation rules were issued in each region, but some of the contents are difficult to adapt to the actual operation needs, and the distribution of benefits must be adjusted by marketoriented means. In order to implement the requirements of the power system reform, to ensure the safety, stability and economic operation of the power system, and to promote the consumption of new energy, all provinces in China have built the peak-control auxiliary service market, and explore the establishment of a new mechanism for sharing and sharing of peak-control auxiliary services.

\section{Market members and responsibilities}

\subsection{Market operating institutions}

As for the market operating institutions, they are generally the provincial power control center and the provincial power trading center. The responsibilities of the provincial power control center and the provincial power trading center in the provincial rules are generally the same. The main responsibilities of the provincial power control center are to manage and operate the peak-control auxiliary service market.

In particular, there are differences in the rules governing the registration and management of market entities in different provinces. For example, in Fujian, the rules specify that the power trading agency is responsible, while in Xinjiang, the rules specify that the power dispatching agency is responsible, and in Shandong, Shanxi and Gansu, the provinces do not specify which department is responsible.

\footnotetext{
a WangXingkai: 15034909739@163.com
} 


\subsection{Market entities}

Power generation enterprises are the most important subjects in the peak-control market. However, due to the different power supply structure, load characteristics, and supply-demand balance in each province, the main body of the peak-control auxiliary service market varies greatly from province to province. For example, Xinjiang market requirements for Xinjiang provincial and above power dispatching agencies directly regulated, and participate in Xinjiang regional electricity balance of grid-connected power plants; Shanxi market requirements for the completion of the main market registration of the provincial transfer of grid-connected power plants. It should be noted that Xinjiang, Gansu, Shandong, Northeast and Ningxia require coal-fired thermal power units to participate in the scope of standalone capacity of $100 \mathrm{MW}$ and above; Xinjiang requires hydropower plants to participate in the scope of installed capacity of 50MW and above, and hydropower plants are only involved in the mediation standby transaction.

\section{Detailed peak shaving trading rules}

Deep peaking refers to the auxiliary service provided by the grid-connected power generating units by reducing their output to below the compensated peaking reference value according to the dispatch instruction of the power grid.

\subsection{Paid peak shaving reference value}

When the load factor of a thermal power unit is higher than the paid peaking benchmark value, it is considered to be uncompensated peaking and does not receive compensation. The compensated peaking benchmark value is a dynamic equilibrium point that reflects the relationship between supply and demand in the market. Currently, the compensated peaking benchmark values for thermal power units in each province are shown in Table 1, with Gansu, Anhui and Ningxia at $50 \%$ of rated capacity, Fujian at $60 \%$ of rated capacity, Shandong at $70 \%$ of rated capacity, and Shanghai at $47 \%$ of rated capacity. In Xinjiang, Shanxi, and Northeast China, the compensated peaking benchmark values are adjusted differently according to the heating period and the type of thermal power units, while in Jiangsu and Jiangxi, the compensated peaking benchmark values are determined according to the peak demand of the grid and the compensation funds for auxiliary services. In addition, the paid peaking benchmark for nuclear power units in Fujian Province is $75 \%$ of the rated capacity, which is higher than that for thermal power units; the paid peaking benchmark for nuclear power units in Shandong Province is $70 \%$ of the rated capacity, which is the same as the paid peaking benchmark for thermal power units.
Table 1. Reference value of paid peak shaving for thermal power units in various provinces.

\begin{tabular}{|c|c|c|c|}
\hline Province & Period & $\begin{array}{l}\text { Type of thermal } \\
\text { power plant }\end{array}$ & $\begin{array}{l}\text { Paid Peaking } \\
\text { Benchmark }\end{array}$ \\
\hline \multirow{4}{*}{ Xinjiang } & \multirow{2}{*}{$\begin{array}{l}\text { Non-Heating } \\
\text { Period }\end{array}$} & $\begin{array}{l}\text { Pure Condensing } \\
\text { Thermal Power Units }\end{array}$ & $50 \%$ \\
\hline & & Cogeneration units & $45 \%$ \\
\hline & \multirow{2}{*}{ Heating Period } & $\begin{array}{l}\text { Pure Condensing } \\
\text { Thermal Power Units }\end{array}$ & $45 \%$ \\
\hline & & Cogeneration units & $50 \%$ \\
\hline \multirow{5}{*}{ Shanxi } & \multirow{2}{*}{$\begin{array}{l}\text { Non-Heating } \\
\text { Period }\end{array}$} & $\begin{array}{l}\text { Pure Condensing } \\
\text { Thermal Power Units }\end{array}$ & $50 \%$ \\
\hline & & Cogeneration units & $50 \%$ \\
\hline & \multirow{3}{*}{ Heating Period } & $\begin{array}{l}\text { Pure Condensing } \\
\text { Thermal Power Units }\end{array}$ & $50 \%$ \\
\hline & & Cogeneration units & $60 \%$ \\
\hline & & & $55 \%$ \\
\hline \multirow{4}{*}{ Northeast } & \multirow{2}{*}{$\begin{array}{l}\text { Non-Heating } \\
\text { Period }\end{array}$} & $\begin{array}{l}\text { Pure Condensing } \\
\text { Thermal Power Units }\end{array}$ & $50 \%$ \\
\hline & & Cogeneration units & $48 \%$ \\
\hline & \multirow{2}{*}{ Heating Period } & $\begin{array}{l}\text { Pure Condensing } \\
\text { Thermal Power Units }\end{array}$ & $48 \%$ \\
\hline & & Cogeneration units & $50 \%$ \\
\hline Shanghai & - & - & $47 \%$ \\
\hline $\begin{array}{c}\text { Gansu / An } \\
\text { hui / Ningxia }\end{array}$ & - & - & $50 \%$ \\
\hline Fujian & - & - & $60 \%$ \\
\hline Shandong & - & - & $70 \%$ \\
\hline
\end{tabular}

\subsection{Quotation and settlement}

The deep peaking auxiliary service market in each province mostly adopts the ladder type and unit-by-unit quotation method, which is divided into several tranches according to the load rate of units, with each tranche being a quotation interval and price limit. In Fujian, Jiangxi and Anhui, there are five tranches according to $5 \%$ of rated capacity; in Shandong, there are seven tranches according to $10 \%$ of rated capacity; and in Xinjiang, Gansu, Northeast and Ningxia, there are two tranches with $40 \%$ of rated capacity as the boundary. Price limitation is one of the market rules that thermal power companies are most concerned about. For example, for thermal power units with $40 \%-45 \%$ load factor, the limit price in each province is shown in Table 2 , with the lowest limit price in the Shanghai market and the highest limit price in the Fujian market. It should be noted in particular that Shanxi does not impose a ceiling on the price quoted, because Shanxi's deep peaking transactions are organized by two-way quoting, centralized competition, rolling clearing and unified price settlement, and when the marginal price of renewable energy generating units is less than the marginal price of thermal power, the transaction is considered not concluded and deep peaking is not invoked. 
Table 2. Price limit for deep peak shaving at $40 \%-45 \%$ load rate of thermal power units.

\begin{tabular}{|c|c|}
\hline Province & Price limit (RMB/MWh) \\
\hline Shanghai & 100 \\
\hline Shandong & 150 \\
\hline Xinjiang & 220 \\
\hline Jiangxi & 300 \\
\hline Ningxia & 380 \\
\hline Gansu/Northeast/Anhui & 400 \\
\hline Fujian & 500 \\
\hline Shanxi/Jiangsu & - \\
\hline
\end{tabular}

\subsection{Cost-sharing}

The deep peaking compensation cost in the peak-control market of each province is generally shared by each market participant according to certain rules, and the difference is mainly reflected in whether the calculation of the sharing ratio is based on the generation capacity or the grid tariff, and whether it is based on the entire generation capacity or the portion of the generation capacity above the compensated peak-control benchmark value.

Xinjiang deep peak adjustment compensation costs are shared by public thermal power plants, wind farms, photovoltaic power plants whose load rate is equal to or greater than the compensated peaking benchmark value, according to the time period of the call; The apportionment rules in Gansu, Ningxia and Xinjiang are similar, except that hydropower is apportioned in the Gansu market, and the hydropower generation capacity is corrected for the heating and non-heating periods; In Shandong and Anhui, the apportionment rules are roughly the same, with thermal power plants, wind farms, photovoltaic power plants, nuclear power plants, and inter-provincial contact lines apportioned according to the amount of electricity generated during the deep peaking period (the amount of electricity received by the contact lines), and thermal power plants apportioned according to the full amount of electricity generated.

\section{Emergency start-stop peak shaving transaction rules}

\subsection{Start and stop time requirements}

Xinjiang and Gansu require thermal power units to start and stop in an emergency for no more than 72 hours. Shandong requires that when the operating units are called to participate in the shutdown for peak adjustment, compensation for peak adjustment will be given if the units are turned on within 24 hours, and the early stoppage and multiple stoppages resulting from failure to strictly implement the dispatching instructions will not be counted. Fujian stipulates that during 00:00-24:00 hours, coal-fired power plants start and stop for one or more times, and hydropower plants start and stop (including idling) for three or more times for peak adjustment, that is, the unit is considered to have completed the start-stop peak adjustment.

\subsection{Quotation and settlement}

On the day before the operation day, thermal power companies offer floating quotations according to the emergency start-stop peaking quotation range corresponding to the rated capacity level of the units, which will be invoked by the power control center according to the needs of the power grid during the day. In Fujian, Shanxi, Jiangsu, Jiangxi, Northeast and Anhui, the quotations are based on the total quotations from low to high, and it is clearly stipulated in the Fujian market that if the quotations are the same, priority will be given to units with large rated capacity. As shown in Table 3, the limit prices in Xinjiang, Gansu, Shanxi, Northeast and Ningxia are close to or even identical, but the limit prices in Fujian, Jiangxi and Anhui are significantly lower than those in the above five provinces, especially that the limit price for a megawatt unit is only about half of the limit price in the above five provinces. Shanghai's market price limit is the lowest among these provinces.

It should be noted that the emergency start-stop trading in Shandong market is different from that in other provinces, which stipulates that thermal power units below the minimum maintenance output of the depth peaking can be shut down for peak quotation separately, and the upper limit is 270 Yuan/MWh, and the calculation of peak power is based on the actual duration of shutdown, and the peak price for each time period during the shutdown is the liquidation price of the corresponding slot at the initial time of shutdown.

Table 3. Emergency start and stop price limit for thermal

\begin{tabular}{|c|c|c|}
\hline Unit rated capacity level & Province & $\begin{array}{c}\text { Price limit (ten } \\
\text { thousand yuan/time) }\end{array}$ \\
\hline \multirow{6}{*}{300 million } & Jiangxi & 35 \\
\hline & Shanghai & 40 \\
\hline & Anhui & 60 \\
\hline & Fujian & 100 \\
\hline & Xinjiang/Gansu/Ningxia & 110 \\
\hline & Shanxi/Northeast & 120 \\
\hline \multirow{5}{*}{600 million } & Shanghai & 50 \\
\hline & Anhui & 90 \\
\hline & Jiangxi & 100 \\
\hline & Fujian & 130 \\
\hline & $\begin{array}{c}\text { Xinjiang/Shanxi/Gansu/ } \\
\text { Northeast/Ningxia }\end{array}$ & 200 \\
\hline \multirow{5}{*}{1000 million } & Shanghai & 60 \\
\hline & Anhui & 120 \\
\hline & Jiangxi & 150 \\
\hline & Fujian & 160 \\
\hline & $\begin{array}{l}\text { Xinjiang/Shanxi/Gansu/ } \\
\text { Northeast/Ningxia }\end{array}$ & 300 \\
\hline
\end{tabular}


Table 4. Various provinces peak shaving auxiliary service transaction varieties.

\begin{tabular}{|c|c|c|c|c|}
\hline Province & $\begin{array}{l}\text { Deep peak } \\
\text { shaving }\end{array}$ & $\begin{array}{l}\text { Emergency start- } \\
\text { stop peak shaving }\end{array}$ & $\begin{array}{l}\text { Electric energy } \\
\text { storage trading }\end{array}$ & $\begin{array}{l}\text { Demand side } \\
\text { resource transaction }\end{array}$ \\
\hline Xinjiang & $\sqrt{ }$ & $\sqrt{ }$ & $\sqrt{ }$ & $\sqrt{ }$ \\
\hline Northeast & $\sqrt{ }$ & $\sqrt{ }$ & $\sqrt{ }$ & $\sqrt{ }$ \\
\hline Shanxi & $\sqrt{ }$ & $x$ & $x$ & $x$ \\
\hline Gansu & $\sqrt{ }$ & $\sqrt{ }$ & $\sqrt{ }$ & $\sqrt{ }$ \\
\hline Anhui & $\sqrt{ }$ & $\checkmark$ & $\sqrt{ }$ & $x$ \\
\hline Fujian & $\sqrt{ }$ & $\sqrt{ }$ & $\sqrt{ }$ & $\sqrt{ }$ \\
\hline Jiangxi & $\sqrt{ }$ & $\sqrt{ }$ & $x$ & $\checkmark$ \\
\hline Jiangsu & $\checkmark$ & $\checkmark$ & $x$ & $x$ \\
\hline Shanghai & $\sqrt{ }$ & $\sqrt{ }$ & $\sqrt{ }$ & $x$ \\
\hline Shandong & $\sqrt{ }$ & $\sqrt{ }$ & $\sqrt{ }$ & $x$ \\
\hline Ningxia & $\sqrt{ }$ & $\sqrt{ }$ & $\sqrt{ }$ & $\sqrt{ }$ \\
\hline
\end{tabular}

\section{Conclusions}

The following conclusions can be drawn from an indepth synthesis and comparison of the operating rules of the provincial power peaking auxiliary services market.

From the provincial peaking rules involving deep peaking and emergency start-stop peaking transaction rules, Xinjiang and Anhui provinces have detailed and specific regulations on market membership, deep peaking involving paid peaking benchmark value, offer and clearing, cost sharing and penalty mechanism, emergency start-stop peaking involving start-stop time, offer and limit price and cost sharing, which are the best in each province. In contrast, Shanxi's rules are the worst among the provinces in that they only provide for the base value of paid peak shaving and quotation and settlement. In terms of the varieties of peaking auxiliary services traded in the rules, Xinjiang, Gansu, Fujian, Ningxia, and Northeast China have the most varieties, including deep peaking, emergency start-stop peaking, electric energy storage peaking, and demand-side resource participation peaking, which are the best in each province. In contrast, Shanxi has only one variety of deep peaking, which is the worst among all provinces. Considering the above two aspects, Xinjiang is considered the most detailed and comprehensive peaking auxiliary service rule. Anhui comes second, and Shanxi is the worst of the above provinces, with much room for improvement.

By combing through the provincial peak-control auxiliary service rules, we can find a direction for the provinces to revise or adjust the auxiliary service rules in the future: each province will continuously expand the scope of market subjects and improve the transaction details for market subjects to participate in auxiliary services based on the national policy on auxiliary services and the characteristics of their own provinces. First of all, in Xinjiang, Northeast China, Gansu, Fujian, Ningxia and other places, there are more auxiliary service transaction varieties, but the existing specific transaction rules on the participation of electric energy storage and demand-side resources in peaking are still very imperfect and need to be further solved; secondly, in Shanxi, Jiangsu, Jiangxi and other places, there are fewer auxiliary service transaction varieties, which need to be combined with the provinces in the future. Finally, what all provinces need to do is to continue to improve the existing trading rules on deep peaking and emergency start-stop peaking, and continuously improve the fairness and rationality of the peaking auxiliary service market from all aspects. For example, if we look at the provincial rules on deep peaking and emergency start-stop peaking, we can see that there is still a lot of room for improvement in terms of the penalty mechanism and start-stop time requirements, and only a few provinces have made clear provisions.

\section{References}

1. MHAMOUDI N, SHAFIE-KHAH M, SAHA T K, et al. Customer-driven demand response model for facilitating roof-top PV and wind power integration[J]. Iet Renewable Power Generation, 1210 (2017)

2. DARAEEPOUR A , KAZEMPOUR $\mathrm{S} \mathrm{J}$, PATINO-EHEVERRI D, et al. Strategic demandside response to wind power integration[J]. IEEE Transactions on Power Systems, 3505 (2016).

3. Wang Z, Zhang B, Zhang Y Determinants of public acceptance of tiered electricity price reform in China: Evidence from four urban cities[J]. Applied Energy, 244 (2012).

4. Teng $\mathrm{F}$, Wang $\mathrm{X}$, Zhiqiang $\mathrm{L} \mathrm{V}$. Introducing the emissions trading system to China's electricity sector: Challenges and opportunities[J]. Energy Policy, 45(2014)

5. Ali Mehdipour Pirbazari Ancillary services definitions, rkets and practices in the world[C]. IEEE/PES Transmission and Distribution Conference and Exposition, 36(2013).

6. Kwok W. Cheung. Ancillary service market design and implementation in North America: from theory to practice[C]. DRPT, April 6-9, 66-73(2019).

7. Palensky P, Dietrich D. Demand Side Management: Demand Response, Intelligent Energy Systems, and Smart Loads[J]. IEEE Transactions on Industrial Informatics, 388 (2011).

8. AGHEB S, TAN X, SUN B, et al. Contract design for aggregating, trading, and distributing reserves in demand-side frequency regulation[J]. IEEE Transactions on Industrial Informatics, 100(2018). 